\title{
Research Article \\ Effect of Briquetting Process Variables on Hygroscopic Property of Water Hyacinth Briquettes
}

\author{
R. M. Davies ${ }^{1}$ and O. A. Davies ${ }^{2}$ \\ ${ }^{1}$ Department of Agricultural Engineering, Niger Delta University, Wilberforce Island, Amassoma, PMB 071, Yenagoa, \\ Bayelsa State, Nigeria \\ ${ }^{2}$ Department of Fisheries and Aquatic Environment, Rivers State University of Science and Technology, Nkpolu-Oroworukwo, \\ Port Harcourt PMB 5080, Rivers State, Nigeria \\ Correspondence should be addressed to R. M. Davies; rotimidavies@yahoo.com
}

Received 21 August 2012; Revised 4 January 2013; Accepted 8 February 2013

Academic Editor: Igathinathane Cannayen

Copyright ( 2013 R. M. Davies and O. A. Davies. This is an open access article distributed under the Creative Commons Attribution License, which permits unrestricted use, distribution, and reproduction in any medium, provided the original work is properly cited.

\begin{abstract}
The knowledge of water resistance capacity of briquettes is important in order to determine how sensitive the produced briquettes are to moisture change during storage. The relative changes in length and diameter of briquettes during immersion in water for 6 hours were investigated. This was conducted to determine hygroscopic property of produced briquettes under process variables levels of binder $(10,20,30,40$, and $50 \%)$ by weight of residue, compaction pressure $(3.0,5.0,7.0$, and $9.0 \mathrm{MPa})$ and particle size $(0.5$, 1.6, and $4 \mathrm{~mm}$ of dried and ground water hyacinth). Data was statistically analysed using Analysis of Variance, the Duncan Multiple Range Test, and descriptive statistics. The relative change in length of briquettes with process variables ranged significantly from $7.21 \pm 0.24 \%$ to $15.62 \pm 3.07 \%$ (binder), $8.58 \pm 0.55 \%$ to $13.97 \pm 2.50 \%$ (compaction pressure), and $6.15 \pm 0.21 \%$ to $17.78 \pm 1.26 \%$ (particle size) $(P<0.05)$. Furthermore, the relative change in diameter of briquettes with binder, compaction pressure, and particle size varied significantly from $2.77 \pm 0.13 \%$ to $3.02 \pm 0.12 \%, 2.58 \pm 0.12 \%$ to $3.31 \pm 0.11 \%$, and $2.64 \pm 0.14 \%$ to $3.17 \pm 0.06 \%$, respectively $(P<0.05)$. This study suggests optimum process variables required to produce briquettes of high water resistance capacity for humid environments like the Niger Delta, Nigeria, as 50\% (binder proportion), $9 \mathrm{MPa}$ (compaction pressure), and $0.5 \mathrm{~mm}$ (particle size).
\end{abstract}

\section{Introduction}

Biomass is an important source of energy for the majority of the population in the developing countries. In Africa, it accounts for $75 \%$ of the total energy consumption [1]. In Nigeria, Ethiopia, Uganda, and Tanzania, biomass accounts for more the $80 \%$ of total energy consumption. The most important sources of biomass fuels in Africa are wood (fuelwood and charcoal), crop and wood residues, and dung [2]. Fuelwood is undoubtedly, the most prominent source of biomass energy, and because of its increasing scarcity, it is a subject of major concern in most developing countries in Africa.

Water hyacinth is an aquatic weed that grows at an extremely rapid rate, and its production is about 2 tons of biomass per acre and doubles every $5-15$ days [3]. Water hyacinth is abundant in most of the fresh water bodies in the Niger Delta areas. Water hyacinth has a potential biomass for production of biofuel because of its high growth yield and availability in large amount throughout the year and all over the world [4]. Water hyacinth was reported to be difficult to control due its spread by physical, chemical, and biological means, and substantial amounts of money have been spent on their control annually throughout the world [3].

The utilization of water hyacinth as an alternative source of energy is an important way of managing the weed problem and contributing to environment management. This might enhance rural economic development, farm income, business diversification, reduction in agricultural surplus, international competitiveness, reduced negative environmental impact, and creation of employment opportunities in the area of production, harvesting, and processing. 
The majority of the rural areas dwellers of Nigeria depend on firewood as a source of energy for cooking [5]. Bioenergy is an alternative and cheap source of energy which can easily be made available to the fish processors in rural areas especially in the Niger Delta in view of fuelwood scarcity.

A binder (additive) can be liquid or solid that forms a bridge, film, matrix, or causes chemical reaction to make a strong interparticle bonding. The strength and durability of densified products depend on the physical forces that bind the particles together [6]. There are three categories of binders, namely, organic, inorganic and heavy petroleum products binders. The binding force that acts between the individual particles in densified products is categorized into five groups. They are solid bridge, attraction forces between solid particles, mechanical interlocking bonds, adhesion and cohesion forces, interfacial forces, and capillary pressure.

In Lindley and Vossoughi [7], briquettes made from sunflower stalk, wheat straw, and flax straw absorbed about $9.9,32.3$, and $38.1 \%$ of water after immersion for 30 seconds in water at room temperature. Li and Liu [8] reported biomass logs made from oak sawdust, pine sawdust, and cottonwood sawdust disintegrated less than 5 minutes after being immersed in water at room temperature. The biomass logs swelled rapidly in the water and disintegrated within a few minutes. These studies showed that short-term exposure to rain would be detrimental to the physical quality of the densified products. The percentage water resistance penetration of carbonized cashew shell, rice husk, and grass briquettes were investigated when immersed in water at $27^{\circ} \mathrm{C}$ for 30 seconds. It was observed that the briquetted fuel from carbonized cashew shell had low percentage water resistance penetration of less than $10 \%$ as compared to the briquetted fuel from carbonized rice husk and grass that had percentage water resistance penetration of about 35 and $45 \%$. The briquetted fuel from carbonized cashew shell required minimum energy for production and low water absorption properties [9].

Tabil [10] reported that increase in moisture content by more than 3-5\% due to storage under high relative humidity (70-90\%) had detrimental effect on durability of alfalfa pellets. During storage, an increase in the moisture content of alfalfa pellets from $7.5 \%$ wet basis (w.b.) to about $12.5 \%$ (w.b.) increased the durability of pellets from 81 to $85 \%$. Furthermore, an increase in the moisture content of alfalfa pellets from $7.5 \%$ (w.b.) to about $19.0 \%$ (w.b.) reduced the durability of pellets from 81 to $75 \%$. That study suggested that a small percentage of increase in moisture content (about $4 \%$ ) could have helped strengthen the bond between the individual particles in the pellet due to the binding forces of water molecules. However, increasing moisture content by more than $4 \%$ increased the volume of the pellet and free water in the particles, which could have reduced the binding forces between the individual particles in the pellet and, thus, a decrease in the durability of pellets.

The water absorption capacity of pellet stored in the environment chamber having a temperature $28^{\circ} \mathrm{C}$ and relative humidity (90\%) for the period of 50 to 80 days after the production showed different water resistance capacities depending on binders and exposure duration to water [9].
The pellet hardness was more sensitive to moisture change during storage than pellet durability [8]. The quality of the briquettes can be affected by the moisture content $[7,11]$. It was observed that strength and bulk density of the briquettes increased with increasing moisture content until an optimum level is reached. Moisture acts as both lubricant and binding agent, but beyond the optimum level of moisture content, the briquetted material would not be compacted, regardless of the pressure level. This could be attributed to the excess water present in the particle surfaces which causes reduction or even complete loss of the surface tension [7]. The moisture content below $20 \%$ was recommended to have stable and durable briquettes [11].

The objectives of this study are to investigate the optimum binder proportion, compaction pressure, and particle size that will produce briquettes with the highest water resistance capacity. Also, this study assessed the suitability of water hyacinth briquettes in high relative humidity areas such as the Niger Delta of Nigeria.

\section{Materials and Methods}

The study area was Port Harcourt, Nigeria. It is a coastal city located at 4.77742 (latitude in decimal degrees) and 7.0134 (longitude in decimal degrees). The average elevation of Port Harcourt, Nigeria, is 468 meters. This City being an equatorial humid area has the highest rainfall value in Nigeria (2000-4000 mm per-annum). High relative humidity values $(\mathrm{RH}>80 \%)$ are encountered in the wet and dry seasons. Low humidity $(<60 \%)$ is only experienced during the Harmattan period.

The water hyacinth samples were harvested manually from a fish pond. Water hyacinth samples were cleaned of foreign matters (i.e., stone, dust, and other plant materials) prior drying. The samples were sundried and milled using hammer mill. A Ro-Tap sieve shaker was used to determine the particle size [12]. The water hyacinth grind was mixed with binders produced from plantain peels until a homogenous mixture was formed. The percentages of binders used in the mixture were $10,20,30,40$, and $50 \%$ by weight of residue, while compaction pressure and particle size ranged from 3.0-9.0 MPa and $0.5 \mathrm{~mm}-4.0 \mathrm{~mm}$, respectively (Table 1 ). The method adopted followed that of Bolufawi [13]. Plantain peels were sundried, ground into powder (particle size $0.075 \mathrm{~mm}$ ) using hammer mill, and sieved with Tyler sieve. It was hydrated with a predetermined quantity of hot water to form colloidal solution of the binder and later boiled. The colloidal solution was constantly stirred until smooth paste was formed. This facilitated the proper agglomeration of the particle. The consistency of the binder was maintained at a fixed level with its concentration in the sample mixture varied at $10,20,30,40$, and $50 \%$ levels of the residue.

Prior to briquetting, the moisture content of the mixed samples was determined using ASABE standard method [14]. Compaction tests on the blend samples were carried out using hydraulic press machine with maximum capacity of 20 tons. A steel cylindrical die of dimension $14.3 \mathrm{~cm}$ length and $4.7 \mathrm{~cm}$ diameter was used for this study. The die was freely filled 
TABle 1: Process variables at different levels of the produced water hyacinth briquettes.

\begin{tabular}{ll}
\hline Process variable & Different levels \\
\hline Compaction pressure & $\begin{array}{l}P_{1}(3 \mathrm{MPa}), P_{2}(5 \mathrm{MPa}), P_{3}(7 \mathrm{MPa}), \text { and } P_{4} \\
(9 \mathrm{MPa}) .\end{array}$ \\
& $B_{1}(10 \%), B_{2}(20 \%), B_{3}(30 \%), B_{4}(40 \%)$, \\
and $B_{5}(50 \%)$. \\
Binder proportion & $D_{1}(0.5 \mathrm{~mm}), D_{2}(1.6 \mathrm{~mm})$, and $D_{3}$ \\
& $(4.0 \mathrm{~mm})$. \\
\hline
\end{tabular}

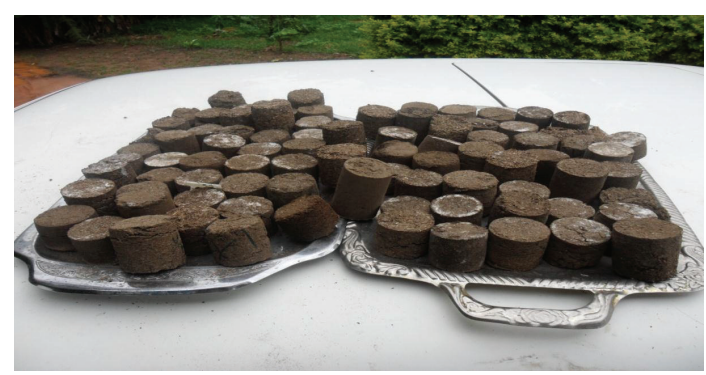

FIGURE 1: Water hyacinth briquettes.

with pre-determined weight of each sample mixture (charge). A known pressure was applied at a time on the material in the die and was allowed to stay for 45 seconds (dwell time) using stopwatch before released, and the briquettes formed were then be extruded. The prepared briquettes were kept for two weeks in the laboratory conditions of temperature $28 \pm 3^{\circ} \mathrm{C}$ and relative humidity of $80 \pm 3 \%$; hence the briquettes could be stabilized. The briquettes were subjected to hygroscopic tests for assessing the water resistance capacity. The relaxed briquettes were immersed in a circular glass container filled with distilled water at temperature of $28 \pm 3^{\circ} \mathrm{C}$ for the period of six hours. Measurements were taken for the length and diameter changes of the briquettes $[5,11]$. Each of the experiments was replicated three times. Figure 1 shows water hyacinth briquettes.

2.1. Data Analysis. The experimental design for this study was $5 \times 3 \times 4$ Randomized Complete Block Design. Each experimental set-up was arranged in Randomized Complete Block Design with three replications per experiment. A total of 180 experiments were conducted. Data was subjected to statistical analyses for analysis of variance (ANOVA), Duncan's Multiple Range Test (DMRT), and descriptive statistics.

\section{Results and Discussion}

The relative change in the length of briquettes during immersion in water for 6 hours was investigated. This was conducted to determine the water absorption capacity (hygroscopic property) of the produced briquettes under process variables of binder, pressure, and particle size. The relative change in length of briquettes ranged between $7.21 \pm 0.24 \%\left(B_{5}\right)$ and $15.62 \pm 3.07 \%\left(B_{1}\right)$, and the variation was significant

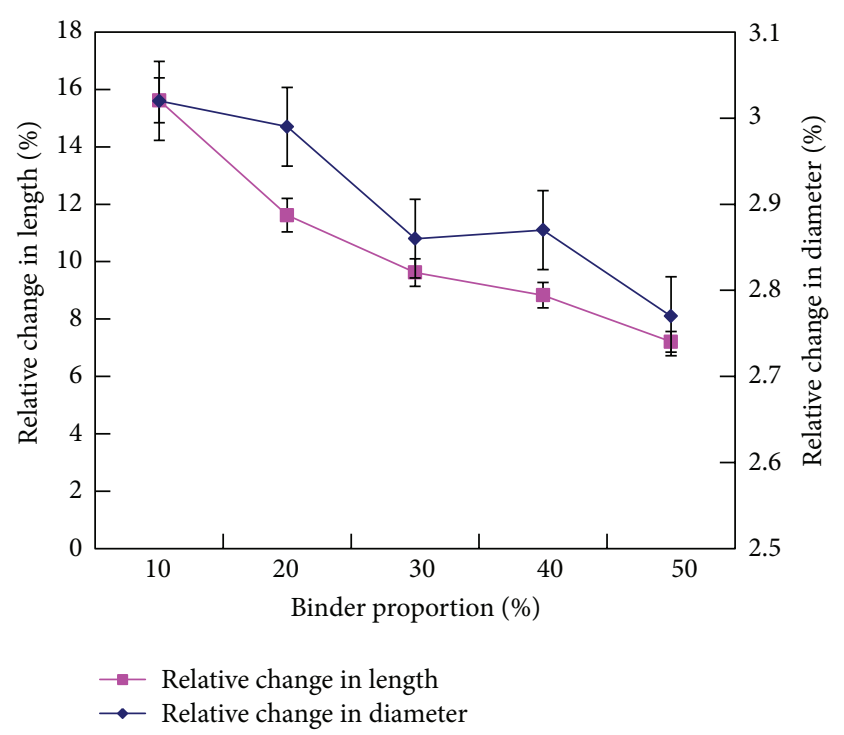

FIGURE 2: Effect of binder on relative change in length and diameter of briquettes.

$(P<0.05)$ (Figure 2$)$. The hygroscopic property of briquettes at different binder proportions showed an increase in water resistance capacity with increased quantity of binder utilized. This is an indication that water hyacinth had high affinity for water compared to the binder (plantain peels). The implication of this observation is that, in high relative humidity areas such as the Niger Delta of Nigeria, briquettes made up of $50 \%$ binder $\left(B_{5}\right)$ might be more suitable and appropriate for production of briquettes. The postimmersion linear expansion of the briquettes ranged between 0 and $10 \%$ after 72 hours of immersion in water for production of briquettes from paper and coconut husk. Briquettes that fall within this range are grouped as low water absorption briquettes [5].

The influence of binder on the relative change in diameter of briquettes is shown in Figure 2. The values varied from $2.77 \pm 0.13 \%\left(B_{5}\right)$ to $3.02 \pm 0.12 \%\left(B_{1}\right)$, and the difference in these values was significant $(P<0.001)$. This is an indication that plantain peels as binder improved the water resistance capacity of the briquettes. The obtained values were lesser than the range obtained for relative change in the length of briquettes. The implication is that, in high relative humidity areas such as the Niger Delta, $B_{5}$ binder level might be more pliable, suitable, and appropriate for production of briquettes.

The effect of compaction pressure on the water resistance capacity of the briquettes was investigated, and it revealed that increase in pressure decreased the water absorption capacity. The values of relative change in length varied between $8.58 \pm 0.55 \%\left(P_{4}\right)$ and $13.97 \pm 2.50 \%\left(P_{1}\right)$ (Figure 3 ). These values were significantly different $(P<0.05)$. The voids between particles inside the briquettes might have sealed up, preventing water infiltration and passage. The recorded maximum compaction pressure $\left(P_{4}\right)$ provided the highest water resistance capacity of the briquettes. Compaction pressure $P_{4}$ might have brought the particles sizes closer 


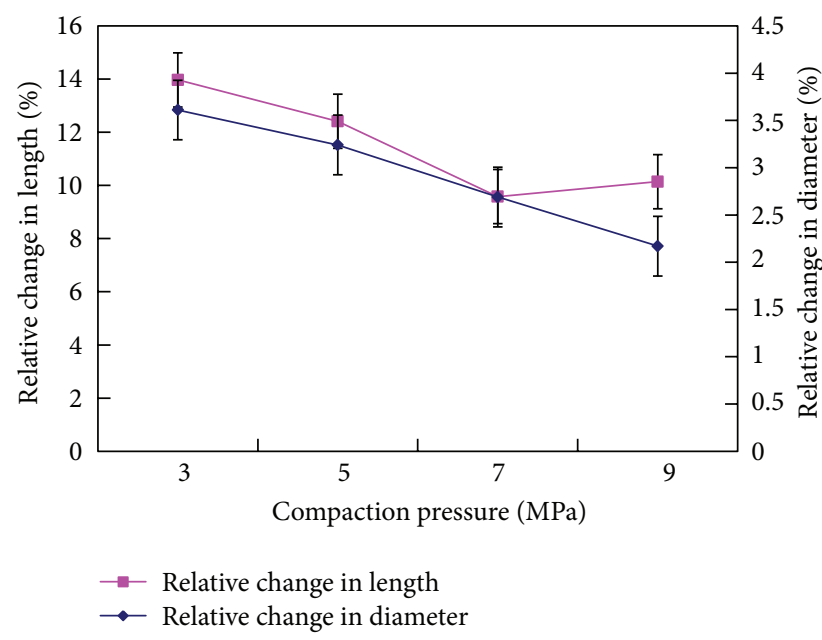

FIGURE 3: Effect of compaction pressure on relative change in length and diameter of briquettes.

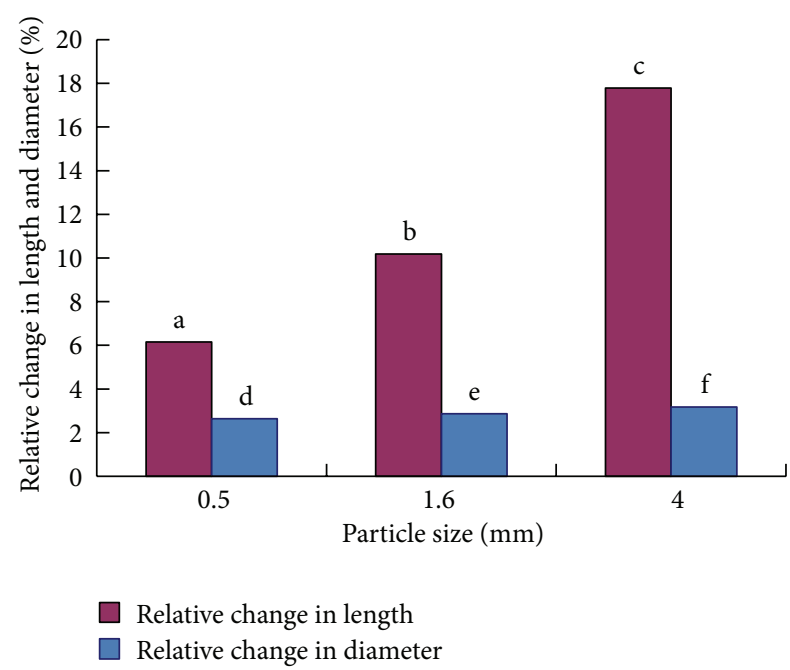

FIGURE 4: Relative change in length and diameter of briquette and particle size. Means of different letters are significantly different $(P<$ 0.05).

so that the forces acting between them became stronger. This could have provided more strength to the densified bulk material so that the product would have sufficient strength to withstand rough handling and humid condition. Thus in a highly humid environment such as the study area pressure $P_{4}$ is recommended.

The interaction between particle sizes and relative change in length varied from $6.15 \pm 0.21 \%\left(D_{1}\right)$ to $17.78 \pm 1.26 \%\left(D_{3}\right)$, and there was significant variation of the values $(P<0.05)$ (Figure 4). The relationship between the particle sizes and relative change in the length of briquettes indicated direct correlation. The particle size is one of the major factors that determine the water absorption capacity of any briquette. The smaller the particle sizes of briquette, the lower the relative change in the length of briquettes. The reason for this observation could be due to particles having interparticle bonding with nearly no inter-particle pores. The briquettes had relatively the highest water resistance characteristic for particle size of $0.5 \mathrm{~mm}$. The implication of this investigation is that the briquettes produced with particle size $4.0 \mathrm{~mm}$ and lower pressure ( $3 \mathrm{MPa}$ ) cannot be stored under high humidity environments such as the Niger Delta areas of Nigeria; hence production of these briquettes are not recommended based on low water resistance and high water absorption capacity of the briquettes.

The effect of compaction pressure on relative change in the diameter of the briquettes immersed in water (Figure 3) varied significantly between $2.58 \pm 0.12 \%\left(P_{4}\right)$ and $3.31 \pm 0.11 \%$ $\left(P_{1}\right)(P<0.001)$. The hygroscopic property of briquettes at different compaction pressure levels decreased with increased water absorption capacity.

The values of relative change in diameter ranged from $2.64 \pm 0.14 \%\left(D_{1}\right)$ to $3.17 \pm 0.06 \%\left(D_{3}\right)$ (Figure 4$)$. The effect of particle size on the relative change in diameter revealed direct proportional. The obtained values of the relative change in diameter of the briquettes were significant $(P<0.001)$. This study showed that short-term exposure to rain would not be detrimental to the physical quality of the briquettes.

\section{Conclusion}

The briquettes that had the highest percentage of water resistance characteristic in terms of length and diameter were obtained from binder level 50\%, compaction pressure $9.0 \mathrm{MPa}$ and particle size $0.5 \mathrm{~mm}$. The hygroscopic property of briquettes at different binder proportions showed increase in water resistance capacity with increased quantity of binder utilized. The smaller the particle sizes of briquettes, the lower the relative change in the length and diameter of briquettes. The water resistance capacity of briquettes progressively improved with increase in binder inclusion and compaction pressure and decrease in particle sizes. It can be concluded that good quality water hyacinth briquettes of high water resistance capacity for humid environments such as the Niger Delta, Nigeria, should be produced with $50 \%$ binder, $9 \mathrm{MPa}$ compaction pressure, and $0.5 \mathrm{~mm}$ particle size.

\section{References}

[1] J. F. K. Akinbami, "Renewable energy resources and technologies in Nigeria: present situation, future prospects and policy framework," Mitigation and Adaptation Strategies for Global Change, vol. 6, no. 2, pp. 155-181, 2001.

[2] B. S. Pathak, "The relevance of biomass management," in Proceeding of the Seminar on Biomass Management for Energy Purposes Issue and Strategies, pp. 1-9, SPRERI, Nagar, Pakistan.

[3] A. Wagner and W. Buscher, "Compression characteristics of wilted grass," CIGR E-Journal, vol. 7, 2005.

[4] M. O. Surrey, "Biomass Energy Centre," 2010, http://www .biomassenergycentre.org.uk.

[5] A. O. Olorunnisola, "Production of fuel briquettes from waste paper and coconut husk admixtures," The CIGR E-Journal, vol. 6, 2007.

[6] N. Kaliyan and R. Morey, "Densification characteristics of corn stover and switchgrass," in Proceedings of the ASABE Annual 
International Meeting, ASABE Paper no. 066174, Portland, Ore, USA, July 2006.

[7] J. Lindley and M. Vossoughi, "Physical properties of biomass briquettes," Transactions of the ASAE, vol. 32, pp. 361-366, 1989.

[8] Y. Li and H. Liu, "High-pressure densification of wood residues to form an upgraded fuel," Biomass and Bioenergy, vol. 19, no. 3, pp. 177-186, 2000.

[9] S. H. Sengar, A. G. Mohod, Y. P. Khandetod, S. S. Patil, and A. D. Chendake, "Performance of briquetting machine for briquette fuel," International Journal of Energy Engineering, vol. 2, no. 1, pp. 28-34, 2012.

[10] L. G. Tabil, Binding and pelleting characteristics of alfalfa [Ph.D. dissertation], Department of Agricultural and Bioresource Engineering, University of Saskatchewan, Saskatoon, Canada, 1996.

[11] O. A. Ajayi and C. T. Lawal, "Hygroscopic and combustion characteristics of sawdust briquettes with palm oil sludge as binder," Journal of Agricultural Engineering and Technology, vol. 5, pp. 29-36, 1997.

[12] R. M. Davies and U. S. Mohammed, "Moisture-dependent engineering properties of water hyacinth parts," Singagore Journal of Scientific Journal, vol. 3, pp. 253-263, 2011.

[13] S. Bolufawi, Briquetting characteristics of guinea corn in relation to fuel value [Ph.D. thesis], University of Ibadan, Faculty of Engineering, Department of Agricultural Engineering, 2008.

[14] ASABE Standards. S269.4, Cubes, Pellet and CrumblesDefinitions and Methods for Determining Density, Durability and Moisture Content, ASABE, St. Joseph, Mich, USA, 2003. 


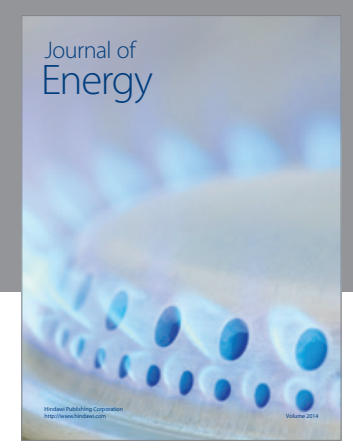

Journal of

Industrial Engineering
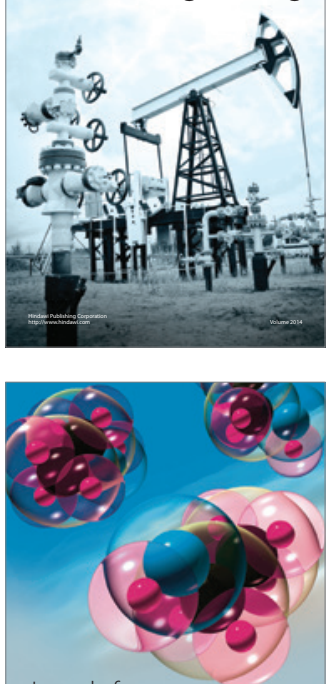

Fuels
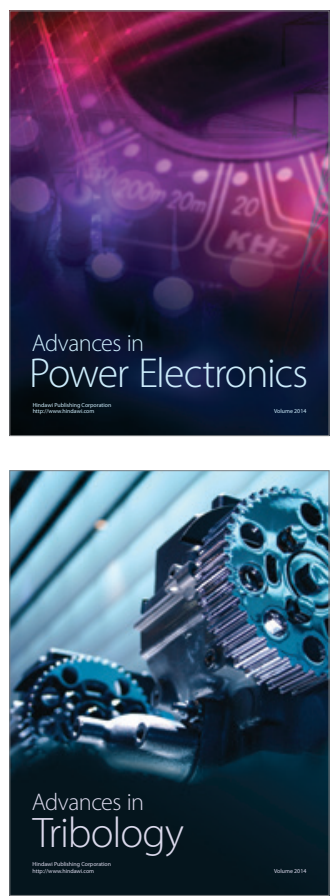

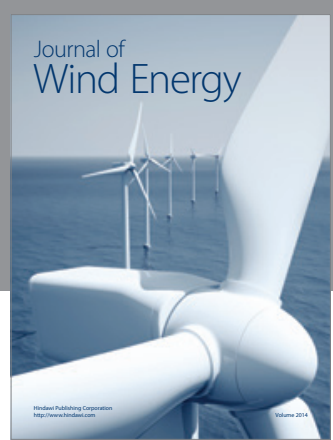

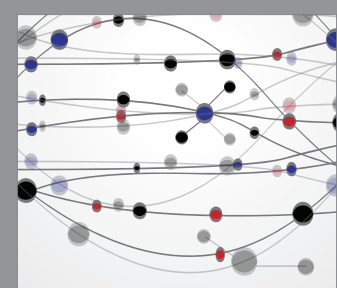

The Scientific World Journal

Submit your manuscripts at http://www.hindawi.com

Journal of

Structures
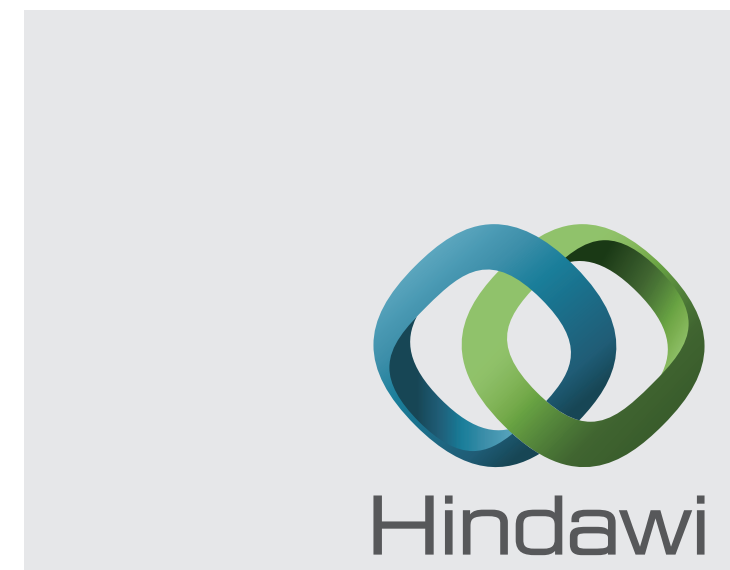

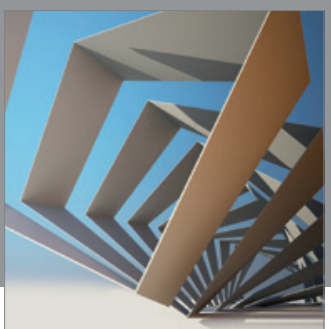

Rotating

Machinery
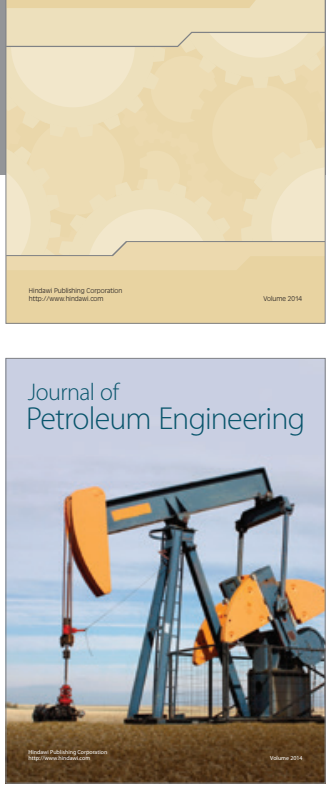

Journal of

Solar Energy
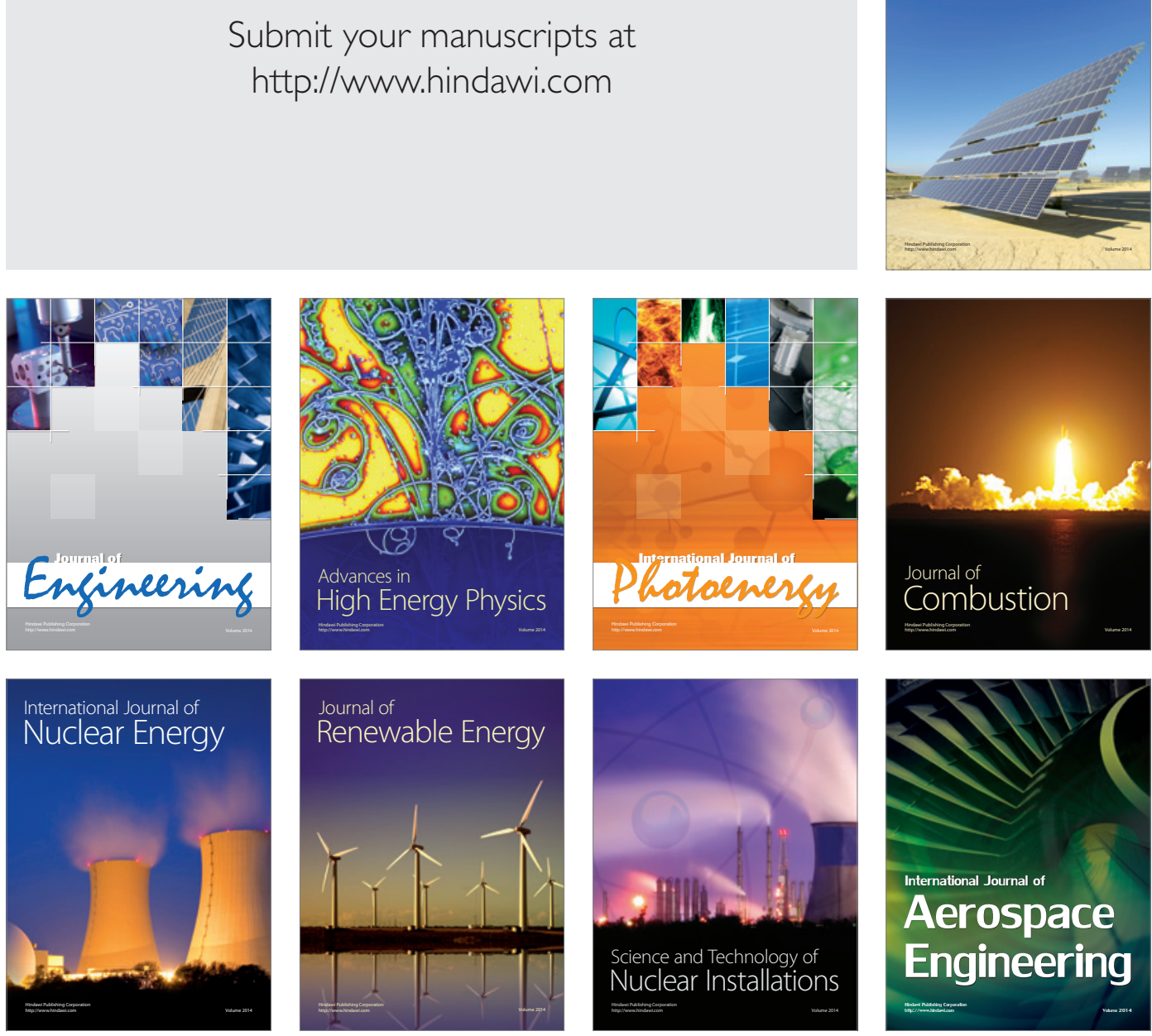